\title{
Cross-Cultural Collaboration for \\ Locally Developed Indigenous Curriculum
}

\author{
JoAnne W. Putnam \\ David E. Putnam \\ University of Maine at Presque Isle \\ U. S. A. \\ Bernard E. Jerome \\ Ramona Jerome \\ Gesgapegiaq First Nation \\ Wejgwapniag School \\ Canada
}

For over 400 years, Wabankaki children of Maine and eastern Canada have been assimilated into schools established by European immigrants. Low high school graduation rates, poor achievement outcomes, and overrepresentation of students in special education reveal an "invisible crisis" that threatens the survival of the indigenous culture and communities. Here we describe a collaborative cross-border project between the Gesgapegiag Mi'gmaq First Nation and northern Maine university professors that produced culturally based curricula in science and early childhood education. Our work involved indigenous ownership, cultural content, language, and instructional strategies.

The Value of Indigenous Knowledge People of the Dawnland

Culturally Responsive Education

Curriculum Planning Process

Reactions to the Curriculum

Conclusion

References

\section{The Value of Indigenous Knowledge}

Indigenous people of North America constitute minority populations with unique challenges. While immigrant minorities are expected to assimilate into the dominant society, enriching it with elements of their cultural backgrounds, indigenous peoples have been required to assimilate to the immigrant's culture. In the US and Canada, an unstated goal of public education has been the assimilation of immigrants and indigenous groups into a mainstream national culture. 
In North American and globally, a lack of consensus exists over the value of indigenous local knowledge for both the "holders of such lifeways and for the broader society":

It is clear in our research that the human knowledge of Indigenous peoples and local communities is failing to become embedded in national education systems because it is seen as lower order knowledge when compared to the superior knowledge system of western industrialized societies. (Ma Rhea, 2004, p.5).

Indigenous knowledge has been accumulated over many thousands of years by sustainable societies on the same landscape that our modern, pluralistic societies now occupy. During this time of worldwide ecological concern and crisis, Indigenous knowledge can offer alternative ways for managing resources and creating more sustainable environments (Emery, 1996). Indigenous local knowledge can play a vital role in building the capacity of an indigenous community to achieve environmental or economic goals, such as maintaining healthy watersheds and forests, sustaining a healthy salmon population, or making and marketing traditional crafts.

The value of indigenous knowledge systems is gaining in recognition from both indigenous and non-indigenous communities.

Indigenous peoples throughout the world have sustained their unique worldviews and associated knowledge systems for millennia, even while undergoing major social upheavals as a result of transformative forces beyond their control. Many of the core values, beliefs and practices associated with those worldviews have survived and are beginning to be recognized as having an adaptive integrity that is as valid for today's generations as it was for generations past. The depth of indigenous knowledge rooted in the long inhabitation of a particular place offers lessons that can benefit everyone, from educator to scientist, as we search for a more satisfying and sustainable way to live on this planet. (Barnhardt \& Kwagley, 2005, p. 9).

Educators and researchers increasingly acknowledge the importance of indigenous knowledge, language and culture in education and its role in academic achievement, cultural survival, and wellbeing (Battiste, 2000; Barnhardt \& Kwagley, 2005; Castagno \& Brayboy, 2008; Demmert \& Towner, 2003). Castagno and Brayboy's (2008) review of the literature concludes that over 40 years of research and writing advocating for culturally responsive schooling for indigenous youth has not resulted in systemic and lasting changes to schools. Moreover, the development and implementation of culturally responsive curricula has not occurred uniformly throughout North America.

This article describes our experience with cross-cultural and cross-border collaboration to develop culturally responsive curricula for a Mi'gmaq First Nation community school. The complexity of working with a First Nation whose geographic boundary historically spans two countries was a unique challenge. It was also challenging to align the curriculum content with provincial and national 
education standards without losing the essence of the local indigenous knowledge, culture, and language.

\section{People of the Dawnland}

For over 12,000 years the Wabanaki, People of the Dawnland, have inhabited the northeastern edge of North America, where the morning sun first rises on the continent (Prins, 1996). Wabanaki children from the Mi'gmaq, Maliseet, Penobscot, and Passamaquoddy Bands/First Nations are educated in both tribal and public schools in Maine and the Canadian Maritime Provinces (i.e., New Brunswick, Nova Scotia, Prince Edward Island, and Quebec). The original Wabanaki territory geographically spanned the contemporary international border. The Jay Treaty (1794) provides members of Canadian First Nations with international border crossing rights and the opportunity for immigration, employment, education and trade in the United States (Prins, 1996). Families are mobile, children often live in both Canadian and US communities, and some alternately attend schools in both countries. The Mi'gmaqs are a sovereign nation in Canada, with separate policies, although their traditional territory spans two other nations (the United States and Canada), each with their separate policies. They are of a nation within a nation, which poses unique and challenging governance and education issues.

The Wabanaki Nations of Maine and eastern Canada have been in contact with Europeans longer than other indigenous North Americans, with the exception of Norse-Inuit encounters and Spanish incursions into the Caribbean and Gulf of Mexico (Prins,1996; Fitzhugh \& Ward, 2000). Vestiges of this legacy persist in the community perceptions and legal relationships between the Wabanaki Nations, Canada, and the United States. The colonial experience preceded the implementation of the US American Indian policy in the western United States or the establishment of Native Corporations in Alaska.

The rural, conservative, English and French speaking societies of Maine and eastern Canada have overtly or covertly adhered to the assumption that assimilation was the ultimate solution to the "problem" of internal indigenous sovereign nations. Non-native citizens, and particularly public school teachers and administrators, generally believed that if Natives would "just get over it" and assimilate, all of the problems associated with Indian Reservations, or nations within nations, would disappear. Yet after more than 400 years of the Wabanaki assimilation experiment in public education, it has not succeeded in solving the problems linked to Indigenous educational attainment. 


\section{Wabanaki Learning Outcomes}

Several indicators of school success include graduation/completion rates, the percentage of students placed in special education, and academic achievement outcomes. Graduation rates for Native American students in Maine lag behind Native American and non-native students nationally. The national report by the U.S. Department of Education (DeVoe et al., 2008) indicates that about $91.1 \%$ of White students and $74.4 \%$ Native American students graduate high school within five years. Based on rates from 2005-06, the four-year graduation rates for "all" Maine students is $75 \%$ and for Maine's Native American students it is $41 \%$ (Alliance for Excellent Education, 2009). In northern Maine, the Aroostook Band of Mi'gmaq Indians estimated their students' graduation rate at $38.7 \%$, and the Houlton Band of Maliseet Indians reported a $45 \%$ graduation rate in 2005 (Carlos, personal communication, November 17, 2010).

In Quebec, the problem of the high dropout rate among Aboriginals (First Nations, Inuit, Métis) is described as "acute" (Richards, 2009). This is especially true for Aboriginals aged 25-35 living on reserves in Quebec, who have about a $50 \%$ high school incompletion rate. In Canada the 2006 Census figures show that about $60 \%$ of First Nations on-reserve residents aged 20 to 24 have not completed high school or obtained an alternative diploma or certificate (Mendelson, 2008; Statistics Canada Website, 2008). Off reserves, the percentage of incompletion is about $28 \%$ according to a study by the C.D. Howe Institute on Social Policy (Richards, 2009).

In Maine the percentage of Native American students receiving special education under the Individuals with Disabilities Act (IDEA) is almost double $(26.5 \%)$ the national average (14\%) for Native Americans/American Indians, and triple the national average (8.3\%) for White students. It is likely that the labeling and over-identification of Native American students is "intertwined with the historic devaluation of minorities in the United States" (Harry and Klinger, 2007, p.16). The percentage of First Nations students with special needs in Quebec ranges from $17 \%$ to $50 \%$, depending on the source and how the special needs categories are defined (Phillips, 2010).

Maine Native American students lag behind their peers with respect to academic achievement. The Maine Educational Assessment (MEA) math scores for eighth graders illustrate the disparity. For 2008-2009, 53\% of all students meet/exceed the standards, and only $36 \%$ of Native American students meet/exceed the standards (Duncan, personal communication, March 24, 2010).

Improvement has occurred in some education outcomes, such as increases in the number of Native American students who go to college, but, on the whole, the situation may fairly be described as an "invisible crisis" in the US (Orfield et. al, 2004). Canadian researchers White and Beavon agree: 
We are facing a crisis. Not only because there is such a large gap between Registered Indians and the rest of Canada. It is not only because all Aboriginal identity populations are achieving much lower attainment. It is all this and more. The crisis comes from the fact we are not improving the situation despite the enormous resources we throw at the problem. The gap is getting worse! (White \& Beavon, 2009, p. 7-8).

The forces influencing educational outcomes for Native American and First Nations students include poverty and social issues, the cultural discontinuity between teachers and students, the lack of Native teachers, and the lack of culturally responsive curricular and instructional approaches (Demmert \& Towner, 2003: Harry \& Klinger, 2007; DeVoe et al., 2008).

\section{Culturally Responsive Education}

An important way to address poor educational outcomes for Native American First Nations students is to engage indigenous and non-indigenous educators in promoting more culturally responsive education. Culturally responsive education preserves indigenous identity and way of life while also preparing students for future economic and political success in the broader pluralistic community. Researchers emphasize that culturally responsive education (also called culturally based education) provides a foundation for learning and future academic achievement (Castagno \& Brayboy, 2008; Demmert \& Towner, 2003; Indian Nations at Risk Task Force, 1991). Demmert and Towner's (2003) research review concludes that formal evidence shows that culturally based education programs with strong Native language programs positively influence a youngster's academic social, and cultural development as well as fostering a sense of identity.

While most of the research on culturally based education is nonexperimental (Demmert \& Towner, 2003), there are studies that meet rigorous quasi-experimental research criteria that show a connection between culturally based education and improved academic performance. For example, the Kamehameha Early Education Program (KEEP) is a longitudinal research project incorporating culturally based instruction and a high-standard academic curriculum that had positive effects on students in reading achievement of young (K-3) Native Hawaiian children (Tharp, 1982).

Historically, the public school curriculum either erased Native American/First Nations history or misrepresented it (Hesch, 1999). Until recently, northeastern North American history books typically began with French and English settlements in the 17th century, ignoring the rich history, culture, and contributions of the Wabanaki who had lived here for millennia. In the all too recent past, we have found that the public school's curriculum, books, materials, and even the environment are devoid of indigenous content and worldview -- the people and culture are invisible. 
In 2001, Maine legislators took a first step in addressing these omissions when they passed LD 291 An Act to Require Teaching of Maine Native American History and Culture in Maine's Schools (LD 291, 2001). LD 291 requires that Maine Native American history and culture be taught in all elementary and secondary schools, both public and private. Ideally, this will provide an opportunity for all children and educators to learn about the Wabanaki and to share successful indigenous educational approaches.

Despite some isolated improvement, the percent of U.S. Native American students whose teachers integrate Native American culture and history in the curriculum varies greatly by schools and teachers. The National Indian Education Study: Part II (Moran \& Rampey, 2008) found greater integration of native language and culture into "high density" schools, where at least $25 \%$ of the students are Native American/Alaska Native (e.g., the Bureau of Indian Affairs (BIA) Schools, reservation schools) versus "low density" schools with less than 25\% Native American/Alaska Native students. Researchers also stress the importance of the local community in playing an active role in developing culturally based curricula and instruction (Demmert \&Towner, 2003).

The impetus for our culturally responsive curriculum development project came in 2000, when we organized a university field trip for the University of Maine at Presque Isle teacher education and recreation majors to the Gesgapegiag First Nation in Quebec. Although the non-indigenous Canadian teacher education students had all grown up near a First Nations reserve, either in Nova Scotia or New Brunswick, previously none had ever visited a First Nation reserve or school. The trip to the Wejgwapniag Elementary School challenged their long-held negative stereotypes and assumptions about First Nations people. Several students who were both surprised and impressed by what they saw expressed their desire to someday teach First Nations students in a public school or a community school like Wejgwapniag Elementary.

We knew that we needed to build bridges and connect our students, faculty, and the university community with the Wabanaki communities on both sides of the border. As our Native American/First Nations enrollment continues to increase, now at about 75 students (6\%), so does our commitment to creating a more culturally responsive campus. Shortly after our trip to Gesgapegiag, a collaborative curriculum development project was initiated by our Mi'gmaq friends, the Cultural Director and his wife (a Head Start teacher), in collaboration with the Gesgapegiag Education Director. The Gesgapegiag Mi'gmaq Band operated school serves about 121 students, Head Start through grade 8, with a staff of 25 . With the goal of developing curricular resources that reflect and incorporate local indigenous content, we worked over 6 years (2002-2008) on two supplemental curricula for the Wejgwapniag School: Plamu Wesit / Leaping Salmon, a grade 8 science curriculum, and Wejgwategemgwei / Our Future, an early childhood curriculum. 


\section{Curriculum Planning Process}

When we first discussed the possibility of the first curriculum development project in 2002, three principles guided our work: rightful ownership, focus on the local community, and a respectful approach to collaboration and consultation. It was our shared belief that indigenous people are the rightful authors of their history, language, and cultural knowledge (Swisher \& Tippeconnic, 1999; Tuhiwai Smith ,1999). We wanted the curriculum to embody the values, knowledge, and language of the local community. We agree with Romero-Little's (2010) principle that cultural self-determination, or the community's cultural and linguistic aspirations for its children, should determine the content of the curriculum. In this case the local community, Gesgapegiag, is located at the mouth of the beautiful Grand Cascapedia River on the Baie des Chaleur. The Grand Cascapedia River supports some of the last great runs of Atlantic salmon (Salmo salar), a species of enormous significance to the Mi'gmaq community.

Co-developing curriculum requires sensitivity, trust, and mutual respect. Respect for the indigenous culture involves understanding that it has developed organically as part of the regional ecology over thousands of years. Decisions about incorporating community cultural traditions, language, and spirituality require great sensitivity. When questions arise over specific language or curricular content, consultation and conversations among community members provide guidance. Regardless of who initiates a curriculum development project, the local curriculum should be determined primarily by the indigenous community. Community involvement provides indigenous design and perspective from respected community members, elders, teachers, administrators, parents and grandparents.

Priorities for our curriculum content were generated with the community. Curriculum development activities occurred in consultation with traditional language speakers, cultural directors, education directors, storytellers, spiritual leaders, the tribal council, and especially Elders. Provincial/state or national education standards and learned society standards also shaped the development of curriculum objectives, and federal funds granted to the community supported the project. To be fully legitimized, the curriculum was submitted to the Tribal Council for approval.

The Plamu Wesit / Leaping Salmon curriculum was encouraged by Chief John Martin who recognized the need for a grade eight science curriculum. The theme of the curriculum reflects community's traditional dependence on salmon and the Grand Cascapedia River. The late Chief John Martin wrote in the Foreword to Plamu Wesit/Leaping Salmon:

For countless generations the Mi'gmaq have had a special relationship with the salmon. It is out of this desire to preserve this relationship that this curriculum came into being. To the Mi'gmaq, the salmon represents 
an important part of life. The salmon is a part of who we are. It remains an integral part of our lives today as it was in the past. It represents the good things that need to be preserved for our future as Mi'gmaq people.

Sovereignty, self-determination, and advocating for aboriginal and treaty rights deserve explicit feature in culturally responsive schooling and curricula (Castagno \& Brayboy, 2008). The Mi'gmaq have a long history of living along the Grand Cascapedia River, where Atlantic salmon have great historical significance in sustaining their community. However, tensions and conflict have arisen, especially in the 1970s when the Canadian government threatened aboriginal fishing rights and tried to take over the management of the Grand Cascapedia. Co-author Jerome had been involved in protests and ultimately negotiations with the Prime Minister of Canada, Pierre Trudeau, to arrive at a collaborative approach to managing the salmon between the Gesgapegiag Mi'gmaqs, local sporting camps, and the federal government.

\section{Curriculum Purpose and Principles}

We agreed that the purpose of the Plamu Wesit curriculum was to strengthen students' knowledge of Atlantic salmon biology and conservation in

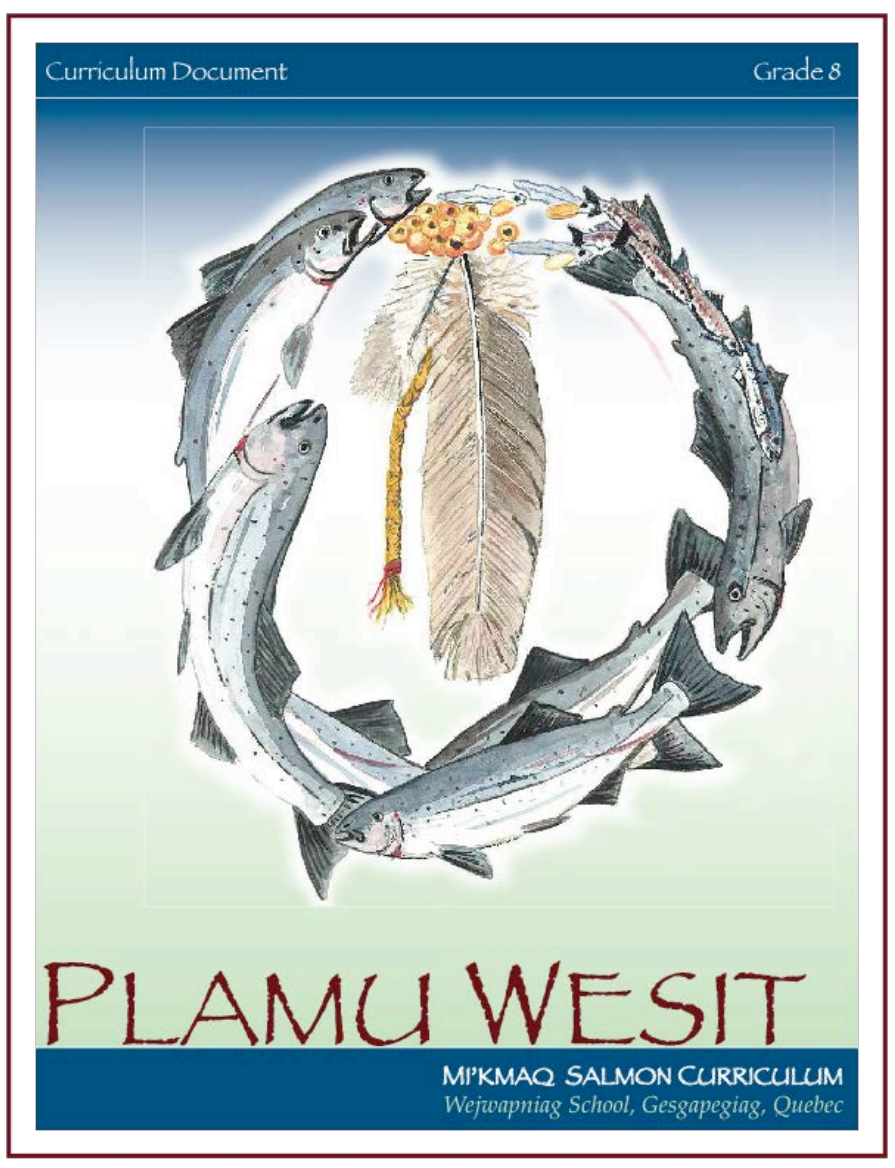

the context of Mi'gmaq culture, traditions, language, values, and beliefs. The salmon theme was suited to this purpose, as salmon beautifully illustrate the cycles of life and the importance of sustaining good relationships with the natural world. Our goal was to design a curriculum that would provide students a beginning background in salmon biology, habitat, migration and conservation. Mythic Mi'gmaq tales and stories would introduce each unit. We identified the content for the curriculum, beginning with the unit on the Grand Cascapedia River watershed. "From Riffles to Rapids," covered the geology and topography of the watershed. A second 
lesson focused on traditional Mi'gmaq place names and their historical importance to survival on the river: food, travel, and virtually every aspect of life connected to the river. Other units covered salmon fishing technologies, the salmon people (indigenous cultures that depend on salmon throughout the world), and protecting the river. Each unit and lesson provided goals tied to science and interdisciplinary outcomes (e.g., biology, geology, hydrology, geography, math, history, ethology [salmon behavior], language, and computer technology). The curriculum also served as a vehicle to introduce Mi'gmaq language to the first generation of Mi'gmaq children to speak only French and/or English.

In addition to designing relevant, culturally appropriate curricula, we were determined that the lessons be rigorous, with high expectations that would set students up for success when they entered the public high school. A previously developed social studies curriculum for the school "sat on the shelves" in disuse, so another goal was to create more dynamic curricula that could be extended and developed over time and accessible online. Local content, such as place names, stories, and interviews with Elders, could be documented and added to the living curriculum. The cover for Plamu Wesit, shown above, was designed to depict the cyclical life of the salmon, from eggs to grilse.

The framework for the early childhood curriculum, Wejgwategemgewei/ Our Future, established major developmental and educational goals and was based on Mi'gmaq values of respect, relationships, initiative, culture, language, joy, and laughter. The guiding principles for the early childhood curriculum are shown in Figure 1, and the cover with a picture of children dancing in a Gesgapegiag pow wow is displayed below.

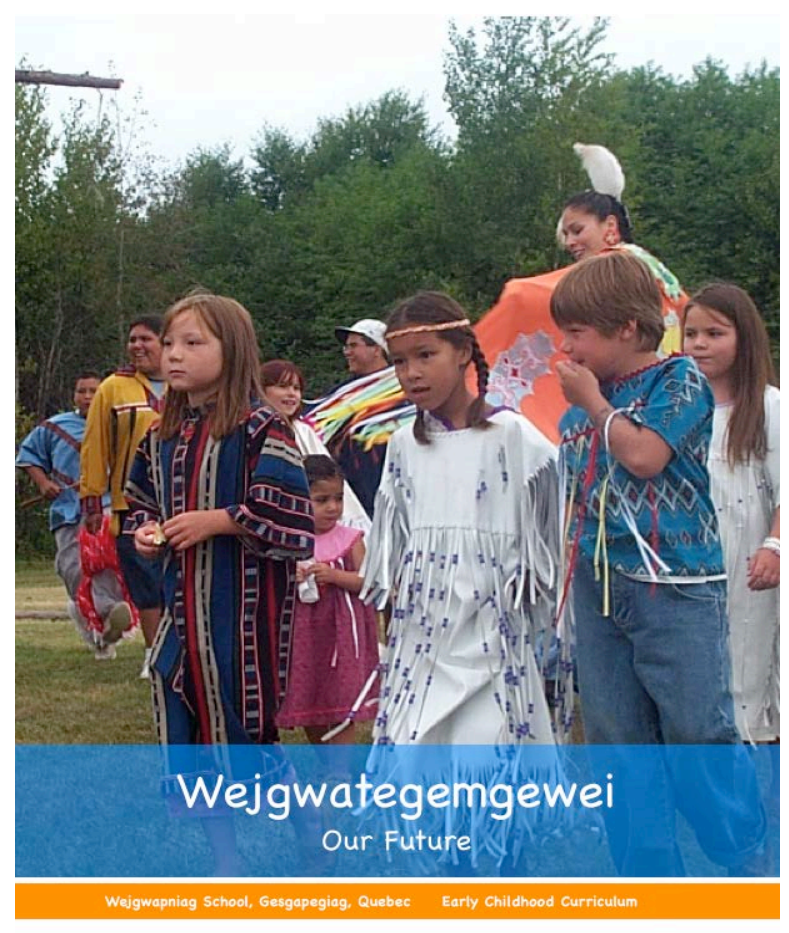




\section{Figure 1. Guiding Principles for Wejgwategemgewei/Our Future}

Culturally Relevant Experiences. The curriculum emphasizes Mi'gmaq community culture, language, knowledge, beliefs, and values. It is tied to the traditions of the community and aimed at building self-respect and a strong sense of identity.

Developmentally Appropriate Curriculum. The curriculum is based on a continuum of typical physical, cognitive, and social development.

Active Learning. Active learning involves physical activity with objects in the environment as well as mental activity as children construct their own understanding of what they are experiencing. Positive adult-child and child-tochild relationships are important in facilitating active learning.

Play. All types of play are integrated into the curriculum, whether it is solitary, parallel play with another child in the same location, interactive play, and cooperative play that involves interaction and negotiation. Games, movement, and creative projects as well as play centers (arts, music, puppets, math, etc.).

Multiple Intelligences. Children are exposed to learning opportunities in all areas of intelligence (linguistic, logical-mathematical, spatial, bodily, musical, interpersonal, intrapersonal, and naturalistic). A child is able to develop various intelligences and can also capitalize on their own area(s) of strength.

Parent/Family and Elder Involvement. Parents are encouraged to become involved with the early childhood center. Kinship and family interactions are important in the learning process. Elder participation is essential, for it is through Elders that the traditions, culture, language, and values are perpetuated.

Language. The incorporation of Mi'gmaq language is a high priority for the community. The preservation and revitalization of indigenous language is seen as nothing less than fundamental to the preservation of their culture.

It was challenging to address Ministry of Quebec standards and best practices in education while also promoting culturally appropriate local curriculum. Provincial/state and national content standards for curriculum are typically developed by and for non-native educators with college degrees and extensive experience. To expect teachers and early childhood staff, some with little or no college preparation, to implement such high standards may be unrealistic. Sometimes tribal schools in rural and remote areas possess limited and inexperienced internal resources. The adequate preparation of indigenous teachers and staff is a matter of national concern in both Canada and the US (Brayboy \& Maughan, 2009). Harvey McCue (2003), past Director and Founder of the Micmac Educational Authority, has called for Indian Education reforms, such as establishing a national infrastructure for First Nations education where 
"curricula and teaching methods will be products of adequately resourced and professional exercises" (McCue, 2003).

\section{Cultural Activities in the Curricula}

Traditional and contemporary Mi'gmaq activities formed the basis of our curricula. The Plamu Wesit /Leaping Salmon curriculum was designed to engage students actively in traditional, contemporary, and future oriented experiences. For example, students are introduced to traditional place-names in Gesgapegiag and the Grand Cascapedia watershed. Place-names are typically descriptive and reflect a profound knowledge about the natural environment, its distinctive geographic features, and natural resources. They play an important role in Mi'gmaq history and describe specific human-landscape relationships (Prins, 1996).

Students create a database on the computer (or an index box) with traditional place names and stories associated with their community's history of activities on the Grand Cascapedia watershed, where the Mi'gmaq have aboriginal fishing rights. For example, Baboq means "calm pool of water," Mtan is "sea." Elders and community members, knowledgeable of the region, are interviewed. Students can record their responses for oral histories and/or film the interviews, with permission. A wall map of the region on the wall in the hallway is provided for students to locate the places with tacks or flags. Posting the placenames on map can continue into the future, with each class contributing to the project. Presentations made to the community, parents, or visitors can be accompanied by recorded nature sounds, or an artistic rendition of a map on a piece of birch bark, in addition to the map display. The computer database will be kept and expanded over time so place-names, associated stories, and the people who are the sources of them can be shared with future generations. When the identification of place-names is complete for the river's upper watershed, the work can continue along the Bay of Chaleur.

The curriculum also covers more contemporary issues related to salmon, such as salmon population decline and habitat destruction. A lesson called "The Meeting" engages students in a Talking Circle to role play a meeting of the Grand Cascapedia stakeholders. Students are assigned various roles which they assume when they discuss their interests and opinions about the future of the river from that particular perspective. Possible roles are a forest products executive, a commercial fisherman, a government representative, a Mi'gmaq fisherman, a river guide, an off-road vehicle enthusiast, or an animal (e.g., bear, eagle, loon, otter, seal, salmon). Researching the assigned roles can take place through interviews, web research, library work, and inviting representatives of a stakeholder group to the class. The Cascapedia River Museum, The Atlantic Salmon Federation, or lawyers with knowledge of Treaty Rights (e.g., Aboriginal Constitutional Treaty Rights) are examples of resources available to students. 
Students read "Gluskap Speaks for Plamu" which is a tale about the mythical Wabanaki character Gluskap and his concern with the present and future survival of salmon and salmon habitat. The science lessons also convey the Mi'gmaq spiritual perspective on the relationships of all things and the importance of balance in the environment.

The teacher or Elder facilitates the Talking Circle, and students have equal status and speak without interruptions. The Talking Circle is a traditional approach to solving problems, conflict resolution, or addressing issues. A Talking Stick or Eagle Feather is passed from person to person in the talking circle. Only the person holding the stick or feather may speak. When a person is finished speaking, he or she says, Nugumah, which is translated as "All my relations." Nugumah refers to all things in this world and the next, and the connectedness of everything. The stick is then passed to the next person. Participants are asked to speak from the heart, show respect for others, and not repeat what is said in the circle outside of the circle.

The Talking Circle is also used each day with opening activities in the early childhood curriculum. It is a time for sharing where children feel a sense of community, acceptance, and support. The teacher may start with a song, greeting, or fingerplay in Mi'gmaq, then the morning message that is sometimes dictated by the children, and then a calendar activity. Sometimes spontaneous events can provide ideas for the Talking Circle, such as migrating geese, Elder stories, a special visitor to the community, a ceremony, or a snowstorm.

The Early Childhood Curriculum teaches Mi'gmaq language, using simple phrases, songs, and rhymes. For example, one lesson plan for story/literacy time is based on the Mi'gmaq book Wiklatmu'j: The Little Person (Julian, 1999). Children learn the Mi'gmaq alphabet, days of the week, family names, songs, rhymes, and phrases. Although the curricula was written in English, as Wejgwapniag is an English school, the early childhood teachers and some community members would like to see the curriculum used with a language immersion approach to build literacy in Mi'gmaq. Currently, the Wejgwapniag School offers Mi'gmaq language immersion classes at the kindergarten and first grade levels.

Family relations and kinship are an important aspect of Mi'gmaq culture. To promote a congruence between the curriculum and family/community life, family, community, and Elder participation were built into the activities. For example, Elders can share their knowledge of holidays, prepare traditional foods, make baskets, net Salmon, teach the language, and share other traditions. Students make and learn rhythms on drums and participate in school and community activities, such as the pow wow.

Oral tradition, through storytelling, Talking Circle, and Elder sharing, as well as other approaches, such as cooperative group learning, active learning, visual learning, and experiential learning in the community and local environment, complement the suite of culturally relevant learning strategies. Our 
approach is learner-centered and emphasizes student-initiated learning and oral tradition of sharing and demonstrating.

Curricular materials developed by and for Mi'gmaqs are used with both curricula: e.g., fiction and non-fiction books, web sites with Mi'gmaq content, and use of an online Mi'gmaq dictionary. Technology and the Internet are used to conduct research and to interact with other "salmon peoples" such as the Tlingit in Alaska or the Saami of Finmark in Norway through e-mail or social networking. Artifacts and cultural objects are also an important part of the curriculum.

\section{Reactions to the Curriculum}

While we did not conduct a formal evaluation of the curriculum, we solicited written feedback from teachers involved with the curricula. The three Early Childhood teachers were asked how they would use the curriculum, what they suggest for cultural activities, what barriers for implementation exist, and who should be involved with the curriculum. They responded that the curriculum was a "great start" and in the future they would like to see it presented entirely in Mi'gmaq and expanded to the Language Immersion Program. They suggested that we develop an assessment tool based on the individual objectives for each lesson, using a checklist and/or rubrics. Ideas for additional cultural activities included honoring the four seasons, ceremonies such as the Sweat Lodge, and material on traditional medicines. They wanted to see more Mi'gmaq culture and language and more cultural activities specific to Gesgapegiag. They felt that the curriculum would have the most impact if the staff involved were expanded to include all the teachers, including the cultural education teacher, the Mi'gmaq language teacher, the entire Head Start and pre-K staff, and any other specialist who teaches. "Everyone must be held accountable," said one teacher.

Barriers to future implementation of the early childhood curriculum were identified as insufficient funding for publishing the curriculum and obtaining proper materials to use with the curriculum. The teachers noted that they would like extra time and support to create lessons and contribute local Gesgapegiag content to the curriculum. Although the early childhood curriculum emphasized the importance of parent/family/Elder involvement, the teachers had difficulty gaining the participation of parents who were often quite young; some were still in secondary school. Also, there were a limited number of Elders from the community who could participate. This is an area needing attention in the future.

The grade 8 teacher who implemented the Plamu Wesit curriculum especially liked the Mi'gmaq vocabulary presented in each section and the Gluskap tales that were woven into the lessons. He felt the involvement of Elders was an important aspect of the curriculum. He noted that the lessons were "straight forward and easy to follow." "It is very nice to have a curriculum for such a distinct culture and area." He appreciated the academic rigor of the lessons. 
Community members have expressed an interest in developing additional supplemental curricula, such as a Mi'gmaq history curriculum. The impact of culturally based curriculum on students could be assessed through evaluation and quantitative research, monitoring academic outcomes with objective measures. Adequate funding and long-term commitment would be needed from the community and educators to carry out research investigations.

In reflecting on the Plamu/Wesit curriculum implementation, Bernard Jerome, co-author of this article, discussed the importance of teaching students about the Gesgapegiag Mi'gmaq history relative to the Grand Cascapedia River. He remembers participating in the government protests in 1975 over the loss of aboriginal fishing rights and the difficult negotiations that ensued. The resulting salmon fishing agreements of 1981 and the formation of the Cascapedia River Salmon Management Society had a profound effect on protecting the river and the 3,000 Salmo Salar that return to their birthplace from across the Atlantic each year. Jerome also emphasizes the economic benefits of the fishing agreement to the Mi'gmaq community:

It's the pride we feel...that we have the right to fish and the responsibility to protect the resource. It affects the economic value of the whole region. The fishing agreement, over the last 30 years, has meant $\$ 30$ million in revenues for the Gesgapegiag community (from employment, hotels, restaurants, outfitters, guiding).

Science, math, economics, environmental protection-it's all connected. That's the Indigenous way of thinking. We can work in parallel with the government, and the middle ground is the result. Students need to see what we have gone through. We need to sensitize all youth (Native and Non-Native) to Mi'gmaq history and culture.

With respect to the future of the curriculum, Jerome asks whether there will be "people who are committed to getting something done" to sustain the initiative. Given the rapid turnover of teaching staff in the school and political changes in the community, it is hard to tell. Turnover is a common problem that is not unique to Gesgapegiag and the Wegjwapniag School, but exists for many tribal and non-tribal schools. "One year it's going great, and then politics change and we start from scratch."

\section{Conclusion}

This collaborative project for curriculum development arose naturally from a friendship between two university professors and two members of the Gesgapegiag Mi'gmaq community. From the perspective of the professors, a major gap exists for Mi'gmaq and indigenous curriculum content in all school curricula, in tribal and non-tribal schools. The lack of this curriculum content further marginalizes Wabanaki children and deprives the non-indigenous students of valuable information about history, culture, values, ways of protecting 
our resources, and inherent respect for an ancient culture that precedes their own. Given the extremely poor educational outcomes for many Wabanaki children in the public schools, there is a strong rationale for promoting culturally responsive education. Since the Mi'gmaq people are the rightful owners of their culture, history, and language, it was essential that they initiated this curriculum project and that they were key contributors.

The nature and process of our collaborative endeavor were unique to the community. Indeed, there is no template for conducting such cross-cultural work. In Plamu Wesit/Leaping Salmon we incorporated Western science and traditional Mi'gmaq knowledge in equal measure and respect for both. In the early childhood curriculum, traditional child-rearing practices were superimposed upon scholarly theory of early childhood development. In both cases, the disparate sources of information were quite compatible and blended to create strong and unique curricula.

This collaboration has contributed to the increased interaction and discourse between the Wabanaki community members with the university and local community. Past relations between the university and the tribes have sometimes been contentious. Shared endeavors, such as curriculum development, are mutually beneficial and expand understanding of Mi'gmaq history and culture. We have arranged for professional development presentations, workshops, drumming, ceremonies, and participation in the annual Native Appreciation Day. Faculty and Band members have been provided joint workshops on curriculum and culturally responsive education to Native programs and public schools.

We anticipate that the curricular material generated will also contribute to the education of non-native students in public schools as much as it has enriched the lives and understanding of the university developers. By making these curricula available to public non-tribal schools, the rich indigenous knowledge accumulated over thousands of years of Mi'gmaq inhabitation can be shared broadly. The core values and beliefs embedded in both curricula illustrate the adaptive integrity and wisdom of a First Nation community that has thrived for generations.

Mi'gmaq Game Warden Joshua Philbrick's powerful words capture the importance of reestablishing a spiritual connection with the earth and the river as well as promoting a positive self-identity. Both goals are important aspects of the Plamu Wesit/Leaping Salmon curriculum.

I had reached the point where I didn't know who I was, he explained. A lot of people are walking around who don't know who they are, because they don't understand their connections, their relations. We believe that all animals are our relations. Every animal has a medicine.... Salmon have the stimulation to not give up," Joshua said. They travel all the way across the Atlantic to spawn here. If people have that connection with the Salmon, they get his medicine, they don't give up. (Shoumatoff, 2006) 
This effort has been a collaborative approach that spanned ethnic, cultural, national, linguistic, and philosophical borders. The resulting curricula are unique in both the manner of their development and the nature and presentation of their content. Indeed, this work represents a very human scale approach to the self-perceived needs of the Gesgapegiag First Nation. It is unique in its content and its geographic, cultural, and historic context. These curricula are products of the community they were designed to serve, and have been envisioned, developed, and vetted by the people whose children will experience them.

\section{References}

Alliance for Excellent Education (July, 2009). Understanding high school graduation rates. Retrieved from http://www.all4ed.org/publication material/understanding HSgradrates

Barnhardt, R., \& Kawagley, A. O. (2005). Indigenous knowledge systems and Alaska Native ways of knowing. Anthropology and Education Quarterly, 36(1), 8-23.

Battiste, M. (2000). Maintaining aboriginal identity, language, and culture. In M. Battiste (Ed.) Reclaiming indigenous vision (pp. 192-208). Vancouver, BC: UBC Press.

Battiste, M. (Ed.) (2000). Reclaiming indigenous vision. Vancouver, BC: UBC Press.

Brayboy, B. M. J., \& Maughan, E. (2009). Indigenous knowledges and the story of the bean. Harvard Educational Review, 79(1), 1-21.

Castagno, A. E., \& Brayboy, B. M. A. (2008). Culturally responsive schooling for indigenous youth: A review of the literature. Review of Educational Research, 78(4), 941-993.

Demmert, W. G., \& Towner, J. D. (2003). A review of the research literature on the influences of culturally based education on the academic performance of Native American Students. Portland, OR: Northwest Regional Educational Lab.

DeVoe, J. F., Darling-Churchill, K. E., \& Snyder, T. D. (September, 2008). Status and trends in the education of American Indians and Alaska Natives: 2008. Washington, DC: U.S. Department of Education.

Emery, A. R. (1996). The participation of indigenous peoples and their knowledge in environmental assessment and development planning. Ottawa, ON: World Council of Indigenous Peoples, Centre for Traditional Knowledge, Canadian International Development Agency.

Fitzhugh, W., \& Ward, E. (Eds.). (2000). Vikings: North Atlantic saga. Washington, DC: Smithsonian Press. 
Harry, B., \& Klingner, J. (2007). Discarding the deficit model. Educational Leadership, 64(5), 16-21.

Hesch, R. (1999). Teacher education and aboriginal opposition. In M. Battiste (Ed.) First Nations education in Canada: The circle unfolds (pp. 179-207). Vancouver, BC: UBC Press.

Indian Nations at Risk Task Force (1991). Indian nations at risk: An educational strategy for action. Final report. Washington, DC: U.S. Department of Education. (ERIC Document Reproduction Service No. ED 339587)

Julian, M. R. (1999). Wiklatmuj: The little person. Retrieved from http://www.firstnationhelp.com/ali/wiklatmuj/

LD 291: An Act to Require Teaching of Maine Native American History and Culture in Maine's Schools (January 25, 2001) Maine State Legislature. Retrieved from http://www.mainelegislature.org/legis/bills/display ps.asp ?ld=291\&snum $=120$

Ma Rhea, Z. (2004). The preservation and maintenance of the knowledge of indigenous peoples and local communities: The role of education. Monash University AARE Conference, Melbourne, Austrailia, November 29-December 2.

McCue, H. (2003). Fixing Indian education. Retrieved from http://www.turtle island.org/discussion/viewtopic.php?t=847

Mendelson, M. (July, 2008). Improving education on reserves: A First Nations Education Authority Act. Ottawa: Caledon Institute of Social Policy. Retrieved from http://www.caledoninst.org

Moran, R., \& Rampey, B., (2008). National Indian education study - Part II: The educational experiences of American Indian and Alaska Native students in grades 4 and 8. National Center for Education statistics, Institute of Education Sciences. Washington, DC: U.S. Department of Education,

Orfield, G., Losen, D., Wald, J., \& Swanson, C. (2004) Losing our future: How minority youth are being left behind by the graduation rate crisis. Cambridge, MA: The Civil Rights Project at Harvard University.

Osterman, K. (2000) Students' need for belongingness in the school community. Review of Educational Research, 70, 323-367.

Phillips, R. (2010). Forgotten and ignored: Special education in First Nations schools in Canada. Canadian Journal of Educational Administration and Policy, 106, 1-26. Retrieved from: http://umanitoba.ca/publications/cjeap/ currentissues.html

Prins, H. (1996). The Mi'gmaq: Resistance, accommodation and cultural survival. New York: Harcourt Brace.

Richards, J. (2009). Dropouts: The Achilles' heel of Canada's high-school system. Vancouver, BC: C.D. Howe Institute. 
Romero-Little, M. E. (2010). How should indigenous children be prepared for learning? A vision of early childhood education for indigenous children. Journal of American Indian Education, 49(1\&2), 7-27.

Shoumatoff, A. (2006). Dispatch \#29: The Grand Cascapedia and its endangered Atlantic salmon, Dispatches from the vanishing world. Retrieved from http://www.dispatchesfromthevanishingworld.com/dispatch29/printerd29.ht $\underline{\mathrm{ml}}$

Statistics Canada Website (2008). Retrieved from http://www.statcan.gc.ca/startdebut-eng.html

Swisher, K., \& Tippeconnic, J. (1999). Next steps: Research and practice to Advance Indian education. Charleston, WV: ERIC Clearinghouse on Rural Education and Small Schools.

Tharp, R. (1982). The effective instruction of comprehension: Results and description of the Kamehameha Early Education Program. Reading Research Quarterly, 71(4), 503-527.

Tuhiwai Smith, L. (1999) Decolonizing methodologies: Research and Indigenous Peoples. New York: Zed Books Let.

White, J. P. \& Beavon, D. (2009) Understanding the current situation. In J.P. White, J. Peters, D. Beavor \& N. Spence (Eds.) Aboriginal education: Current Crisis, Future Alternatives (pp. 3-12). Toronto, ON: Thompson Educational Publishing. 